\title{
Social Factors associated with Relapse in Psychotic Patients Attending Teaching Hospitals in AL-Furat Al-Awsat Governorates
}

\author{
Ali A. ALHatab ${ }^{1}$, Saja H. Mohammed ${ }^{2}$ \\ ${ }^{1}$ Ph.D. Student - ${ }^{2}$ Prof. Dr. Department of Psychiatry and Mental Health Nursing, College of Nursing, University \\ of Babylon, Hillah City, Iraq
}

\begin{abstract}
Background: The relapse in mental disorders is extremely painful and costly for the patient and his family as well as for the community. These frequent readmissions are strain on the health institutions and on the Ministry of Health Budget.

Objectives: To find out the relationship between the social factors of relapse and sociodemographic data of psychotic patients attending teaching hospitals in AL_Furat Al-Awsat Governorates.

Methodology: The design was (Descriptive-Correlational) used to describe the variables and the relationships that occur among them in this study. The sample was (a non-probability) purposive of (181) relapsed psychotic patients were selected from our patients centers from teaching hospitals in AL_Furat Al-Awsat Governorates, during the period from $9^{\text {th }}$ May 2019 to $20^{\text {th }}$ August 2019. The instrument included two parts: sociodemographic variables and the social factors associated with relapse. The researcher used descriptive statistics tools such as frequency, percentage, mean of score and used in inferential statistics such as Chi-Square.
\end{abstract}

Results: The findings of the study indicate that $(45.86 \%)$ of the sample their diagnosis was schizophrenia, $(25.97 \%)$ were schizoaffective and $(11.60 \%)$ were major depressive disorder with psychotic features. Also, the findings of the study indicate that $(58.6 \%)$ of the study samples they have poor social factors, while $(24.3 \%)$ they have moderate social factors and (17.1\%) they have good social factors.

Conclusion: There is a high significant relationship between the most sociodemographic data and social factor (that included family support and financial factors).

Keywords: Social Factors, Relapse, Psychotic patients.

\section{Introduction}

According to the American Psychiatric Association (APA), the mental disorder defines as a health state described by high dysfunction in-person behavior, emotions, cognitions or that reflect a disorder in the psychological, biological or developmental processes following mental functioning (1). Relapse is recurrent through the beginning years of the disease which may be associated non-compliance to treatment and regain symptoms that lead to an increase in the danger of relapse more than 5 times. The occurrence of relapse with psychotic patients living with their families depends largely on follow-up, how to treat and what the family provides them ${ }^{(2)}$. Psychotic relapse is the recurrence of treated psychotic symptoms and causes the patient's condition is deteriorating and cause hospital readmission ${ }^{(3)}$. Can be serious outcomes for clients and families during relapse at an early phase of psychosis. The functional outcomes consider the most visible result of relapse and there is have a relation with interruption of remission. The most important predictor of functional consequences (social relationships, employment, and school) length of remission join negative and positive 
symptoms which have been shown to be by far at 1 - and 2-years follow-up of patients with early-phase psychosis (4). The major goals and challenges to the client and their families were relapse prevention (2). Relapse may be poor to affect their consequences for a long time and affect social interaction and occupational growth. Analyzes indicated that the treatment of relapses of psychosis would be very costly and estimated to be four times the cost of care for individuals without relapse ${ }^{(5)}$.

\section{Objectives}

1. To assess the type of diagnosis with most relapse rate.

2. To identify the social factors that contributes with most relapse clients.

3. To find out the relationship between the social factors of relapse and sociodemographic data of psychotic patients.

\section{Methodology}

ü Design of the study: A descriptive-correlational was used to describe the variables and the relationships that occur among them in this study. This design was carried out to accomplish the aims of this study using assessment method on psychotic patients attending the out patients clinic of teaching hospitals in AL_Furat AlAwsat Governorates, during the period from $9^{\text {th }}$ May 2019 to $20^{\text {th }}$ August 2019.

ü Sample of the study: The sample was (a nonprobability) purposive of (181) relapsed psychotic patients were selected from teaching hospital out patients center in AL_Furat Al-Awsat Governorates.

ü Study instrument: A questionnaire was created by the researcher to reach the study objectives. A large body of relevant literature were extensively reviewed to find the appropriate tool for the current study.

All the instrument domains are measured and rated on three levels rating as a 3-point Likert scale from 1 to
3 respectively; 1 indicates never, 2 indicates sometimes, and 3 indicates always.

The social factors associated with relapse of patients with psychotic illnesses are determined based on the mean of items scores. Effect levels of these domains were measured as follow:

- $\quad($ Low effect $=1-1.66($

- $\quad$ )Moderate effect $=1.67-2.33($

- $\quad$ )Sever effect $=2.34-3$ ).

ü The instrument included two parts: sociodemographic variables and the social factors associated with relapse.

\section{Part1: The Socio-demographic information:}

This part includes: (gender, age, age at diagnosis, duration of disease, level of education, social status, occupation, monthly income, type of living, residence, family type, who give care to the patients, number of relapses, admitted to the hospital, type of diagnosis).

\section{Part 2: Social Factors associated with relapse:}

Includes the association social factors with psychotic patients relapse:

Ø Social Factors: consists of (18) items, divided to (2) domains:

- Family support (10 items).

- Financial factors (8 items).

Data Analysis: The results of the study were analyzed and assessed using the Statistical Package for Social Sciences program (SPSS, Version 26). The researcher used descriptive statistics tools such as frequency, percentage, mean of score and used in inferential statistics such as Chi-Square. 


\section{Results}

Table 1: Descriptive the samples according to types of diagnosis.

\begin{tabular}{|l|l|l|}
\hline Diagnosis & $\mathrm{f}$ & $\%$ \\
\hline Schizoaffective & 47 & 26 \\
\hline Schizophrenia & 83 & 45.9 \\
\hline $\begin{array}{l}\text { Major depressive disorder with } \\
\text { psychotic features }\end{array}$ & 21 & 11.6 \\
\hline Bipolar Disorder & 16 & 8.8 \\
\hline Delusional Disorder & 6 & 3.3 \\
\hline Postpartum Psychosis & 5 & 2.8 \\
\hline $\begin{array}{l}\text { Substance/medication-induced } \\
\text { psychotic disorder }\end{array}$ & 3 & 1.7 \\
\hline Total & 181 & 100 \\
\hline
\end{tabular}

This table shows $(45.9 \%)$ of the sample their diagnosis was schizophrenia, $(26 \%)$ were schizoaffective and $(11.6 \%)$ were major depressive disorder with psychotic features.

Table 2: Social Factor associated with relapse of psychotic patients.

\begin{tabular}{|l|l|l|l|}
\hline No. & \multicolumn{2}{|l|}{ Factors Domains } & \multicolumn{2}{l|}{} \\
\hline $\mathbf{1}$ & $\begin{array}{l}\text { Levels (Social } \\
\text { Factors) }\end{array}$ & F. & $\%$ \\
\hline 1 & Good & 31 & 17.1 \\
\hline 2 & Moderate & 44 & 24.3 \\
\hline 3 & Poor & 106 & 58.6 \\
\hline & Total & 181 & 100 \\
\hline
\end{tabular}

This table shows as regarding social factors, the study samples $(58.6 \%)$ they have poor social factors, while $(24.3 \%)$ they have moderate social factors and $(17.1 \%)$ they have good social factors.

This table shows that there is a highly significant relation in (gender, age, duration of disease, social status, occupation, monthly income, family type and who give care to the patients) with (Social factors) at $\mathrm{p} £$ 0.05 . While this table shows that there is non-significant relation in (age at diagnosis, level of education, type of living, residence, number of relapses and admitted to the hospital) with (Social factors) at $\mathrm{p}>0.05$

\section{DISCUSSION}

The results shows that (45.9\%) of the study samples have schizophrenia, (26\%) have schizoaffective and $(11.6 \%)$ have major depressive disorder with psychotic features. (Table 1). This result comes with (fikreyesus, et al.,2016) they found that (72.5\%) have schizophrenia, (14.2\%) have brief psychotic and (13.3\%) have schizophreniform and schizoaffective (3). Also, this result was agree with (Hui C, et al, 2013) who found that nearly one-fourth $(n=70)$ of respondents with diagnosis of schizophrenia had relapse ${ }^{(6)}$. This is due to the fact that first episode psychosis showed that the diagnosis of schizophrenia was associated with high risk of relapse and elevated severity level, also the nature of the disease according to previous studies, is more severe and less responsive to treatment and suffer many relapses.

The social factors included (family support and financial factors). (Table 2). The result of our study shows that $(58.6 \%)$ of the study samples they have poor social factors, while $(24.3 \%)$ they have moderate level of social factors and (17.1\%) they have good level of social factors. This result may be due to the fact that psychosis increases the family burden because of the difficulty of dealing with the patient and their refusal to take the medication prescribed by the doctor often, and also revealed that the lack of adherence to treatment is because of the high cost of the drug and the weak economic situation of the families and caregiver can't buy it, so these families leave treatment and use of other incorrect methods of dealing with this disease.

The result also shows that there is a high significant relationship in social factors with gender at $p$ value (.000). This result was disagree with (Hussien, et al., 2008) they found non-significant relationship between factors related to family and gender ${ }^{(7)}$. This result may be because our community thought about stigma especially with female patients which lead them to keep them in the home instead of sending them to the hospital.

The result shows that there is a high significant relationship in social factors with age at $p$ value (.000). (Table 3). This result was disagree with (Hussien, et al., 
2008) they found non-significant relationship between factors related to family and age ${ }^{(7)}$. This is because most of the samples in the study were between the ages of 38-47 years who were significantly affected by social factors.

The result shows that there is non-significant relationship in social factors with age at diagnosis at $\mathrm{p}$ value (.080). (Table 3). This result was agree with (Hussien, et al., 2008) they found non-significant relationship between factors related to family and age at diagnosis ${ }^{(7)}$. This is because that psychotic disorder often significant appears earlier in men than in women, and the patients are generally affected in the twenties to early thirties years of old.

The result shows that there is a high significant relationship in social factors with duration of disease at $\mathrm{p}$ value (.001). This result may be due to the fact that the short duration of the disease will lead to poor adaptation to the disease because of the difficulty acceptance of the illness by the patient and the family, since most of the samples in our study were from the duration of the disease (1-4 years) which is the shortest duration in the study so, we see the majority of social factors are significant affected by the duration of the disease.

The result shows that there is non-significant relationship in social factors with level of education at $\mathrm{p}$ value (.270). This result was agree with (Hussien, et al., 2008) they found non-significant relationship between factors related to family and level of education ${ }^{(7)}$.

The result shows that there is a high significant relationship in social factors with social status at $p$ value (.001). This result was disagree with (Hussien, et al., 2008) they found non-significant relationship between factors related to family and social status ${ }^{(7)}$. This is due to the reason most patients in the study were separated and more likely to relapse for several reasons, including the loss of help and loss of independent and the loss of hope for healing through treatment, leading the patient resort to witches and charlatans.

The result shows that there is a high significant relationship in social factors with occupation at $\mathrm{p}$ value (.000). This result was disagree with (Hussien, et al., 2008) they found non-significant relationship between factors related to family and occupation ${ }^{(7)}$. While this result was agree with (Chaurotia, et al, 2016) they found that unemployment was more significant relapse group with unemployment ${ }^{(8)}$. This result may be due to the support of most studies to the real fact that the lack of a job leads to the poor economic status of the family and therefore the family is inability to buy treatment and thus relapse of the patient and persistence of his poor condition.

The result shows that there is a high significant relationship in social factors with monthly income at $\mathrm{p}$ value (.000). This result was disagree with (Hussien, et al., 2008) they found non-significant relationship between factors related to family and monthly income (7). This result may be because of patients' dependence on their family and may be due to the fact that low level of employment leads to lower income for the patient's families, which can lead to poor attendance in the hospital as well as the poor economic status of the families, which has led to the lack of support for their patients and consequently recurrent relapse ${ }^{(9)}$.

The result shows that there is non-significant relationship in social factors with type of living at $\mathrm{p}$ value (.643). (Table 3). This is due to the fact that most of the study sample live with their families like parents or brothers and most of them have housing so there is no relationship with the high rate of relapses.

The result shows that there is a high significant relationship in social factors with family type at $\mathrm{p}$ value (.001). These results were disagree with (Hussien, et al., 2008) they found non-significant relationship between factors related to family and family type ${ }^{(7)}$. This is due to the fact that most of the study samples live with single families and isolated from any social communication and these families are very interested in the secrecy of their son's illness and this is one of the reasons that has a role in the recurrence of the patient's relapse.

The result shows that there is a high significant relationship in social factors with who give care to the patients at $\mathrm{p}$ value (.004). This result was disagree with (Hussien, et al., 2008) they found non-significant relationship between factors related to family and person responsible for the patient ${ }^{(7)}$. This result may be due to the fact that all the previous studies support that the psychiatric patient, especially in psychosis, needs to be followed up by the family, but most of the samples in this 
study were followed by their brothers, so the brothers were the main reason for the recurrence of relapse due to poor follow-up and neglect and not to give them treatment and the adoption of incorrect methods and far from treatment, such as witches and charlatans.

The result shows that there is non-significant relationship in social factors with number of relapses at $\mathrm{p}$ value (.195). This result was disagree with (Hussien, et al., 2008) they found a significant relationship between factors related to family and number of relapses ${ }^{(7)}$.

The result shows that there is non-significant relationship in social factors with admitted to the hospital at $\mathrm{p}$ value (.290). This result was agree with (Hussien, et al., 2008) they found non-significant relationship between factors related to family and type of admission (7). This result may be due to the fact that psychotic patients who weren't compliant to treatment do have increased risk for violence. This is due to the result of most of the patients in the study who violently violated them before admitting to the hospital and receiving treatment for the first time and very affecting their social relationships, especially if the target of the violence is the employer or a family member, friend or teacher and husband. Therefore, most families are forced to bring the patient for not tolerating the harm of the patient to others. Family use in this manner increases the severity and relapse of the illness.

\section{Conclusions:}

The majority of samples were diagnosed with schizophrenia. The greater of samples were among the most affected factors in the study were poor social factors. There is a high significant relationship between the most sociodemographic data and social factor (that included family support and financial factors).

\section{Recommendations:}

1. AL_Furat Al-Awsat region: It is a large area where educational hospitals are available, but it is free of Psychiatric Units that psychiatric patients need treat patients in those area.

2. Educate patients families and society about accepting mentally ill as a member in the society and give education about how to deal with stress and home care for patients.
Financial Disclosure: There is no financial disclosure.

Conflict of Interest: None to declare.

Ethical Clearance: All experimental protocols were approved under the Department of Psychiatry and Mental Health Nursing and all experiments were carried out in accordance with approved guidelines.

\section{References}

1. Townsend M. Essential of psychiatric mental health nursing. Concept of care evidence-based practice. Sixth edition. Philadelphia, FA. Davis Company. 2015: 418-454.

2. Weret Z S, Mukherjee R. Prevalence of Relapse and Associated Factors in Patient with Schizophrenia at Amanuel Mental Specialized Hospital, Addis Ababa, Ethiopia: Institution Based Cross Sectional Study. 2014; 2(1): 184-192.

3. Fikreyesus M, Soboka M, Feyissa G T. Psychotic relapse and associated factors among patients attending health services in Southwest Ethiopia: A cross-sectional study. BMC Psychiatry. https:// doi.org/10.1186/s12888-016-1076-2. 2016; 16(1): $1-10$.

4. Jordan G, Lutgens L, Joober R. The relative contribution of cognition and symptomatic remission to functional outcome following treatment of a first episode of psychosis (FEP). J Clin Psychiatry. e566-e572. doi: 10.4088/ JCP.13m08606. 2014; 75(6)

5. Alvarez $M$, Priede $A$, Hetrick $S$ E, Bendall $S$, Killackey E, Parker A. Risk factors for relapse following treatment for first episode psychosis: a systematic review and meta-analysis of longitudinal studies. Schizophrenic. 2012;139 (1-3): 116-28.

6. Hui C, Tang J, Leung $\mathrm{C}$, Wong $\mathrm{H}$ Y, Chang $\mathrm{C}$, Chan K W. A three-year retrospective cohort study of predictors of relapse in first episode psychosis. Aust N Z J Psychiatry. 2013;47(8):746-53.

7. Hussein H A, Jacoob S. Assessment of Association Factors with Risk of Relapse in Schizophrenic Patients at Psychiatric Hospital in Baghdad City. Journal of Education and Practice. Retrieved from https://files.eric.ed.gov/fulltext/EJ1099559.pdf . 2008; 7(10): 40-47.

8. Chaurotia V K, Verma K K, Baniya G C. A Study of Psychosocial Factor Related with Relapse. 
https://doi.org/10.9790/0853-1504142634. 2016; 15(4): 26-34.

9. Goulding S M, Chien V H, Compton M. Prevalence and Correlates of School Drop-Out Prior to Initial
Treatment of Non affective Psychosis: Further Evidence Suggesting a Need for Supported Education. Schizophrenic Res. 2010; 116:228-33. 